\title{
Article \\ Drawing the complexity of Colombian climate from non-extensive extreme behavior
}

\author{
Isabel Hoyos ${ }^{1, * \text { @0000-0001-5178-0447 and Boris A. Rodríguez }}{ }^{1}$ \\ 1 Instituto de Física, Grupo de Fundamentos y Enseñanza de la Física y los Sistemas Dinámicos. Universidad \\ de Antioquia. Medellín, Colombia \\ * Correspondence: isabel.hoyos@udea.edu.co; Tel.: +574 2195630
}

Version February 20, 2019 submitted to Preprints

\begin{abstract}
We evaluate the complexity of Colombian climate from extreme behavior of gauge temperature and precipitation, using the the novel Tsallis' non-extensive entropy principle based on physical information through the q-index. We find the spatial structure of non additive universal categories (q-index) and compare with some complex systems with the potential to have some degree of dynamical affinity. Our results evidence the great dynamical variability of regional climate expressed in the large range of values of $q$-index, and the high degree of non-extensitivity for both temperature and precipitation.
\end{abstract}

Keywords: Colombian climate complexity, climate extremes, Tsallis' non-extensive statistical mechanics, universal categories.

\section{Introduction}

From a dynamic point of view, climate extremes are critical phenomena emerging from spatio-temporal multi-scale interactions. Long-term memory, high degree of information content and persistent positive feedback are some of the necessary conditions to drive the system far from equilibrium and exhibit extreme behavior [1-3]. As part of the Earth system, climate exhibits inherent complexity [4-6] and it is expected a better performance in modeling and predictability from non-Gaussian stochastic approach, via entropic characteristics [7-9].

The Tsallis' non-extensive statistical mechanics is a modern extended theory built on the fact that physical states in phase space from complex processes correspond to a more general entropy than the established by the classical Gaussian thermodynamical equilibrium, since ergodicity (and statistical equilibrium as its macroscopic manifestation) is just one of the dynamic possibilities of microscopic mixing in complex systems [10-16]. In practical manners, the generalization from Tsallis' theory introduces a non-extensive entropic functional through the index $q$ which identifies non additive universal categories and provides physically based information about the underlying dynamics, revealing crucial features about spatio-temporal long-range correlations emerging in extremes $[11,15,17,18]$.

The Tsallis' theory is being progressively applied in complex systems. In particular relative to geophysical processes: turbulence [19], estuarine hydrodynamics [20], ozone layer [21],earthquakes [22], geopotential height [23], global climate [24], ENSO [25,26], hydrological extremes [27,28], regional climate [29-31], among others. In agreement with [17], the success of Tsallis' theory in representing complex systems is mostly due to the extension of the physical representation of the underlying universal organizing principle through a non-extensive entropy formulation that provides a measure of dynamical organization (or information content).

In this contribution, we focus on Colombian climate complexity description from a non-extensive statistical formulation. As previously discussed in [32], [33], [34] and [35], Colombia is located over 
a very active region in terms of atmospheric moisture transport across Americas. The long-term hydrologic teleconnections, the great intra-annual variability of the atmospheric moisture contributions and the heterogeneity of orographic interactions, are some of the factors that have been identified as regional sources of climate variability and extreme events. However, there is still great uncertainty related to underlying dynamics and there is not a previous measure of regional climate complexity based on observations. We present the spatial distribution of $q$ index for temperature and precipitation extreme behavior, which can be interpreted as a complexity property of regional climate. This findings provide useful information about the nature of local physical processes for regional climate modeling.

This paper is organized as follows: Section 2 gives a general description of study area and its climatic and extreme features. Section 3 describes the statistical model applied. Results are shown in Section 4. Finally, concluding remarks are presented in section 5.

\section{Study area and data}

This research is focused on Colombia (Fig 1). This country is characterized by a great landform heterogeneity due to the splitting of the Andes mountain chain in three branches. As a result, the country exhibits a mixed landscape that includes snow peaks, highland plateaus, deep canyons, large rainforest areas and wide valleys, among others. Accordingly, a great ecosystem variability and a large biodiversity are also a footprint for the Colombian terrain. Further, the country is surrounded by the basins of rivers Amazon and Orinoco, and the Pacific ocean and Caribbean sea. A complex interplay between these geographic particularities and regional circulation is responsible for a large variability of rainfall patterns [32,33,35-37], compromises the atmospheric transport across Americas [32-34,38] and leaves a great regional sensibility to global climate phenomena [32,34,39-47].

The four Colombian catchment basins Caribbean, Pacific, Orinoco and Amazon have been becoming in classical units of hydrological and climatic analysis since each one has the proper size for ensuring the closure of the water balance and also, annual cycle of temperature an precipitation have qualitative similarities across each one [48-51]. In the other hand, these hydrological units have had differentiated development paths. While the inter-Andean region has been the central pole of the country's development, the remaining areas have been marginalized in terms of social, cultural and economic growth. This situation is portrayed in the national weather network. Distribution, availability and quality of gauge stations are limited. The best sampled region in Colombia corresponds to Caribbean Colombian catchment (especially in the inter-Andean region) and southern Colombian Pacific catchment.

The study of extreme behavior of climate requires large enough time series for statistical analysis, that is why we have fitted our target region to the Caribbean and Pacific Colombian catchment basins. The Amazon and Orinoco catchment basins are not considered in this work because their limited observational time series despite their environmental and eco-hydrological regional importance. This lack of information is often overcome by using data in the state of art, as reconstructed fields, reanalysis and model output. However, these datasets have limitations in the representation of Colombian climate (especially referred to extremes), mostly because of the available spatial resolution is still being insufficient to represent the great land-form variability and local climate processes $[33,48,52,53]$. In this sense, we rather extract information from gauge observations to provide dynamic clues that can help to determine which model configuration is better for a more realistic representation of the Colombian climate. 


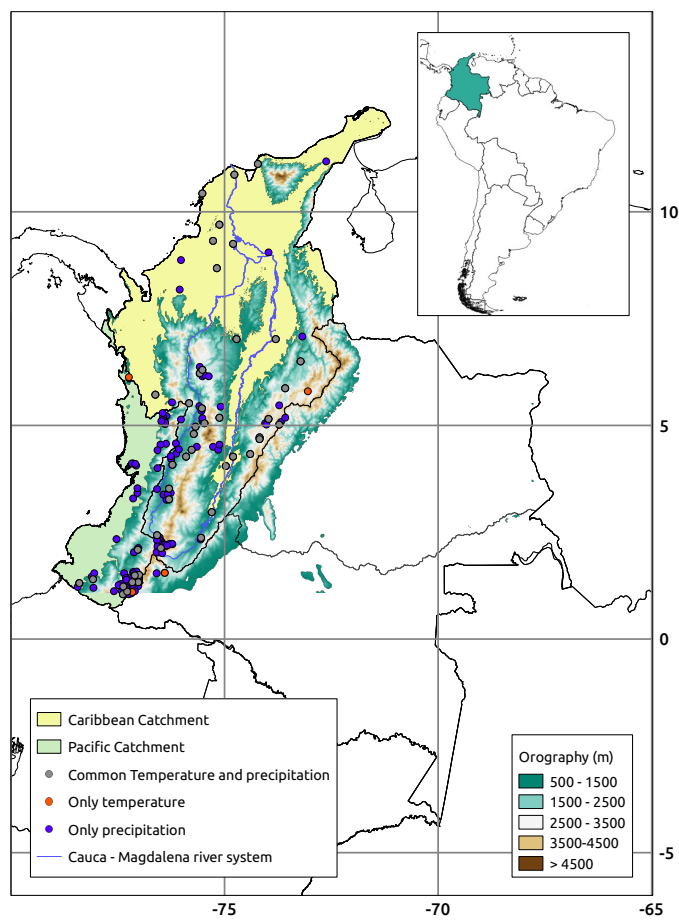

Figure 1. Study area. Points correspond to locations of gauge stations across Caribbean and Pacific Colombian catchments. Orography from Global Land One-kilometer Base Elevation GLOBE [54].

\section{3. Statistical model}

As a generalization of the Boltzmann-Gibbs thermodynamic entropy $\left(S_{B G}\right)$, Tsallis [55] proposed an entropy function $S_{q}$ that better describes complex systems whose phase space is not ergodically visited and therefore the extensive property of thermodynamic entropy is violated. For instance, in systems regulated by several spatio-temporal scales as climate. This new entropy function has the generic form:

$$
S_{q}=k_{B} \frac{1}{q-1}\left[1-\int_{\Omega}[f(x)]^{q} d x\right] ; q \in \mathbb{R},
$$

where $k_{B}$ is the Boltzmann's universal constant, $\Omega$ is the state space represented by the variable $x \in \mathbb{R}^{n}$, and $f(x)$ is the probability density function. $q$ is an entropic index that characterizes the universality classes of non-additivity [14] and describes the deviation of Tsallis entropy from the standard Boltzmann-Gibbs entropy, more precisely, the emergence of long-range interactions, long-term memory and/or multi-fractal behavior [2]. From this new definition of entropy and applying proper constraints, a set of generalized distribution functions are obtained through the maximum entropy principle. In the limit case $q \rightarrow 1$, Tsallis' distributions converge to classical distributions $\left(S_{q} \rightarrow S_{B G}\right)$ [56].

The normalized q-exponential distribution satisfies the maximum entropy principle for $S_{q}$ with constant mean as constraint, which is defined in [57] as:

$$
f_{q, \beta}(x)=\frac{1}{Z_{q, \beta}} e_{q}(-\beta x),
$$


where $Z_{q, \beta}=1 /(\beta(2-q))$ is the partition function with $0<q<2$ and $e_{q}(-\beta x)=$ $(1-\beta(1-q) x)^{1 /(1-q)}$ is called q-exponential function. $\beta$ is a positive scale parameter associated to the distribution mean $\mu$ through $\beta=1 /(\mu(3-2 q))$ for $q<3 / 2$. If $q<1$, the $q$-exponential function has an upper boundary in $x=1 /(\beta(1-q))$ and is unbounded if $1<q<2$.

Supposing that the state of the system is described by the random variable $X$ whose excesses $Z=X(t)-u \mid X>u$ are defined over a enough high threshold $u$ so that $Z$ represents the tail distribution of $X$. In agreement with [57], if $X$ follows a q-exponential probability density $f_{q, \beta}(x)$ its excesses remain having a q-exponential distribution $f_{q^{\prime}, \beta^{\prime}}(z)$, where:

$$
q^{\prime}=q \quad \text { and } \quad \beta^{\prime}=\frac{\beta}{1-\beta(1-q) u} .
$$

The q-exponential distribution is particularly interesting because it provides the information of $q$-index from the excesses set. The definition of climate extremes as the set of excess over a high threshold allows an statistical description in terms of a Generalized Pareto (GP) distribution via asymptotic limit for heavy tails (Fréchet domain) in accordance with [58]:

$$
f_{\sigma, \xi}(z)=\frac{1}{\sigma}\left(1-\frac{\xi z}{\sigma}\right)^{1 / \xi-1},
$$

$\sigma$ and $\xi$ are the GP distribution parameters. $\sigma$ is a positive scale parameter that gives information about the variability and central value of excesses. $\xi$ is a dimensionless shape parameter, which is referred to the shape and bound of the distribution. If $\xi>0$, the GP distribution has an upper boundary in $z=\sigma / \xi$. If $\xi \leq 0$, the distribution is unbounded. The GP distribution becomes to the exponential distribution when $\xi \rightarrow 0$ and the uniform distribution when $\xi \rightarrow 1$.

As both $f_{q^{\prime}, \beta^{\prime}}(z)$ and $f_{\sigma, \xi}(z)$ belong to Fréchet domain, they are directly linked through the relations:

$$
q^{\prime}=\frac{2 \xi-1}{\xi-1}=q \quad \text { and } \quad \beta^{\prime}=\frac{1-\xi}{\sigma} .
$$

This procedure permits the estimation of non-extensive parameters from the extreme behavior of the system.

\section{Results}

Figs 2 and 3 present the spatial layout of the q-exponential distribution function parameters for monthly gauge temperature and precipitation excesses over a non-stationary threshold, within the period 1930-2009. This data were calculated from the GP distribution parameters reported in [41]. Here we focus on excess over 90th percentile as a good agreement between the extreme behavior representation and enough sample length for statistical purpose.

The estimated parameter $q$ shows large spatial variability. In the entire region $0<q^{\prime}<3 / 2$ for both temperature and precipitation, laying in the range of expected value of excesses $\mu^{\prime}$ defined by the scale parameter $\beta^{\prime}$ as $\mu^{\prime}=1 /\left(\beta^{\prime}\left(3-2 q^{\prime}\right)\right)$. However, qualitatively differences were found in the Caribbean and Pacific Colombian basins.

For temperature (Figs 2 and 4a), values of $q$-index in the Caribbean basin area range from 0.22 to 1.31. 59\% (39\%) of gauge stations have $q^{\prime}<1\left(q^{\prime}>1\right)$ that define bounded (unbounded) $q$-exponential distributions. Only $2 \%$ of sampling data are in the canonical exponential function limit $\left(q^{\prime}=1\right)$, evidencing a high degree of non-extensitivity in regional temperature. In contrast, the Pacific basin has $q$-index values in a narrower interval, ranging from 0.75 to 1.15 . Bounded and unbounded $q$-exponential 
141 142

distributions are in equal proportion and neither sampling point with $q^{\prime}=1$.

$q^{\prime}$

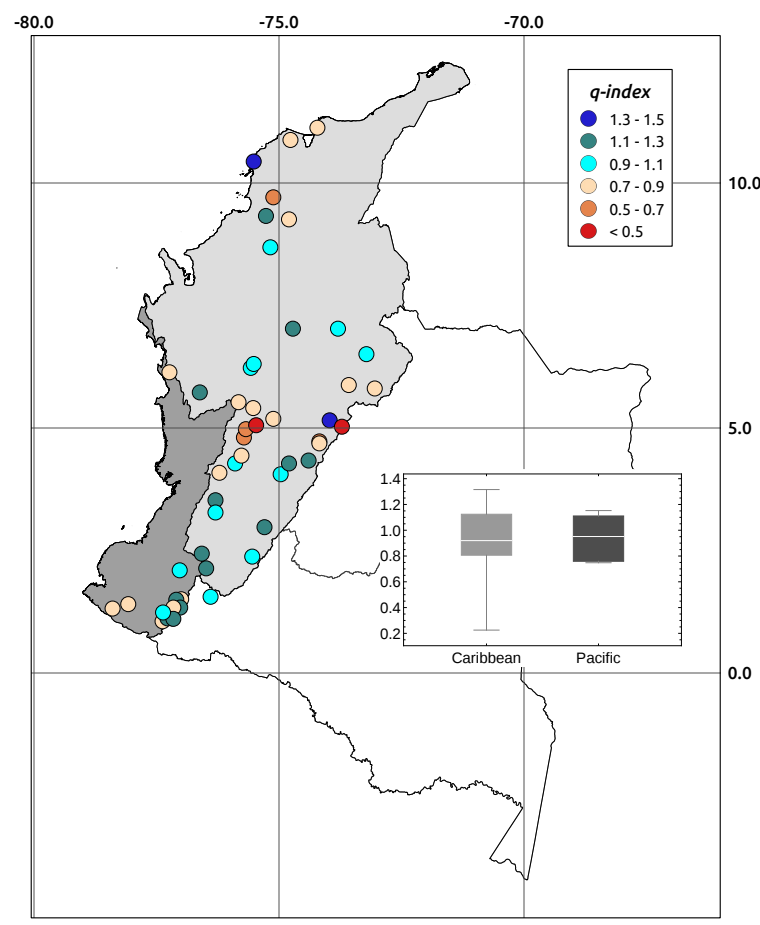

$\mu^{\prime}\left({ }^{\circ} \mathrm{C}\right)$

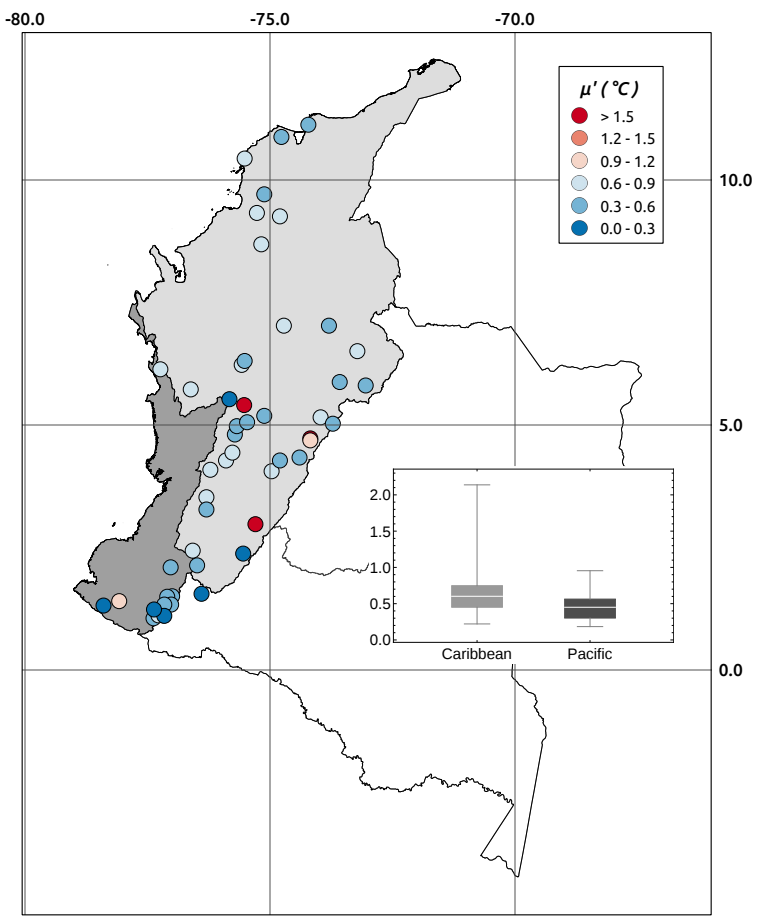

Figure 2. Parameters for the q-exponential distribution function for temperature excesses over non-stationary 90th percentile. (a) $q$-index. (b) expected value for excesses set. The inset boxes show minimum, maximum and the three first quartiles of parameters for Caribbean and Pacific Colombian basins.

For precipitation (Figs 3 and $4 \mathrm{c}$ ), the study area covers $q$-index values from 0.49 to 1.46. In the Caribbean basin ranging from 0.49 to 1.41 with $25 \%$ of stations with values $<1$, while in the Pacific basin $q$-index ranges from 0.72 to 1.46 , with $15 \%$ of bounded distributions. In both basins, the percentage of stations with $q^{\prime}=1$ is near to $8 \%$, remaining a significant non-extensive character of regional precipitation.

Figure $4 \mathrm{~b}$ compiles previous results for some systems with the potential to have some degree of dynamical affinity with our studied system. Here, we refer to dynamical affinity in terms of universality concept as coincidence or similarity in the $q$-index value since the connections we are looking for overtake the particular details of any specific mechanism and revel a kind of order in real-world systems. Regional temperature and precipitation cover the range of q-index reported for last glacial global climate temperature [24], the ENSO [25,26], Ozone layer dynamics [21], rainfall extremes [27] and Couette-Taylor turbulence [17]. This is a benchmark for values of $q$-index in typical climate-related complex systems and establishes a context that allows us to highlight two primary aspects: i) the great dynamical variability of regional climate expressed in the large range of values of $q$-index, and ii) the high degree of non-extensitivity for both temperature and precipitation. These results are in agreement with previously obtained in [31] for daily precipitation in a smaller region and shorter period in tropical Andes. 
$q^{\prime}$

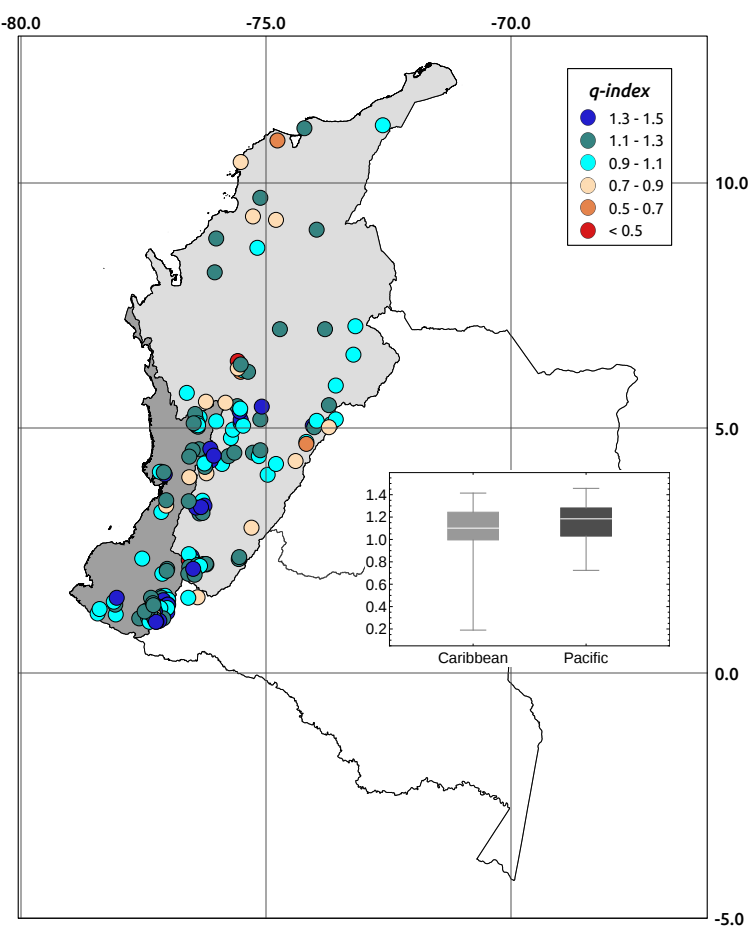

$\mu^{\prime}(\mathrm{mm} /$ day $)$

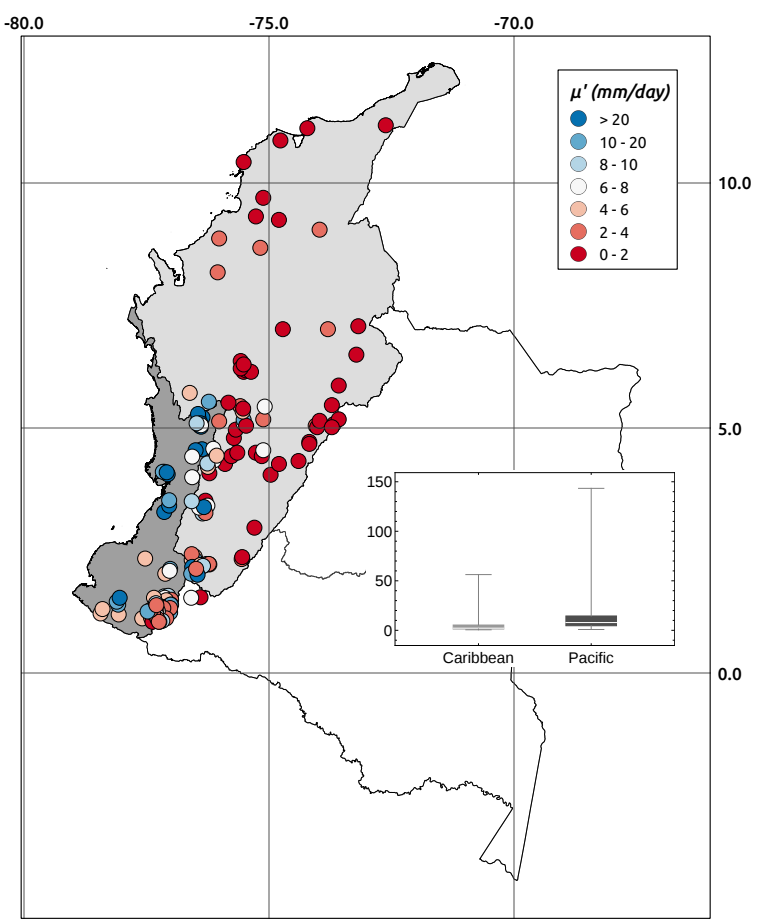

Figure 3. As Figure 2 but for precipitation.

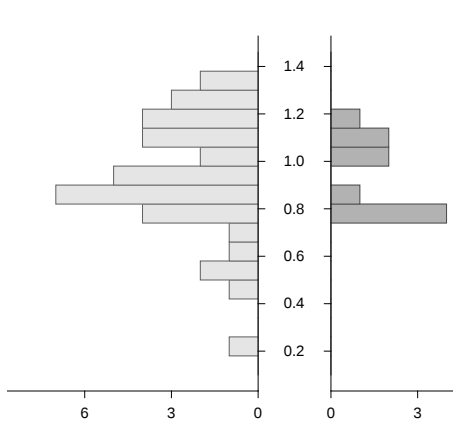

b.

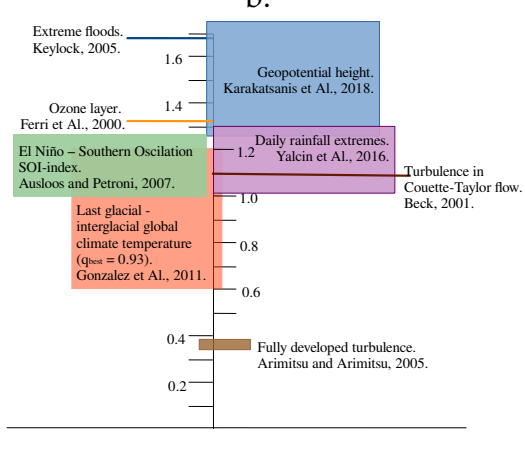

c.

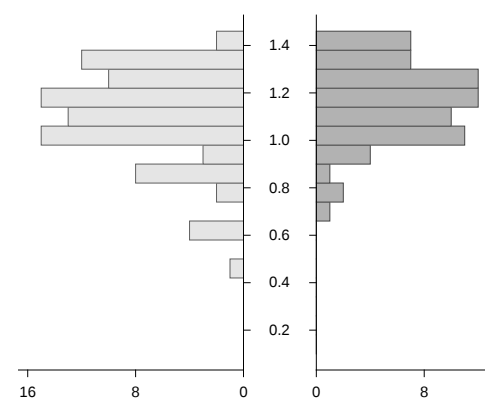

Figure 4. Regional extreme q-index in the context of dynamic universality classes. (a) q-index histogram for temperature. (b) q-index summary for typical climate-related systems. (c) q-index histogram for precipitation. In (a) and (c) light (dark) gray for Caribbean (Pacific) Colombian basin.

Fig 5 compares $q$-index for stations with available information of both temperature and precipitation. The regional extreme behavior of temperature and precipitation is frequently related to global climate phenomena as ENSO [32,39,41,44,47,59]. In this sense, similar $q$-index values could be expected for both variables, however we find that kind of coincidence for just a few stations. The common case is same location has significant different $q$-index values for temperature and precipitation. This result means that dynamics related to global phenomena is expressed in a different kind of complexity for both variables, mostly because of local processes are influencing in a strong manner how the long-term phenomena are locally expressed in each variable. This result is in agreement with obtained in [32] through information transference theory. 


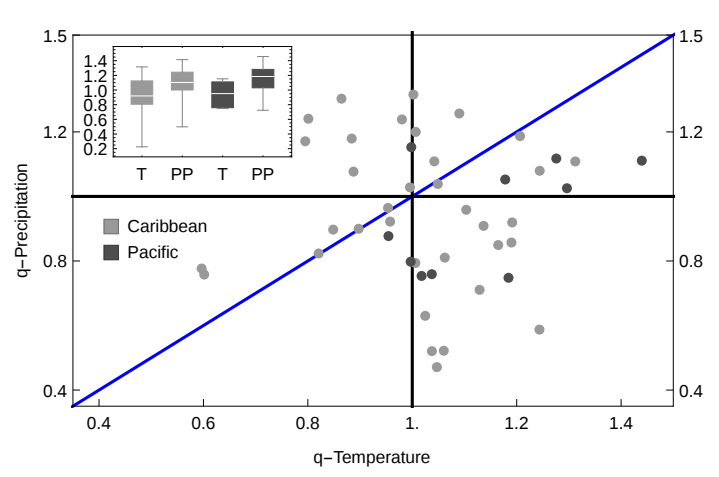

Figure 5. q summary 2. Common stations: 36 for Colombian Caribbean Catchment; 10 for Pacific Colombian Catchment.

\section{Conclusions}

In this contribution we evidence the non-extensive property of regional climate from the extreme behavior. A clear signature of this non-extensive character is the great portion of gauge stations with $q^{\prime} \neq 1$ compared to stations with $q^{\prime}=1$, for both temperature and precipitation. This implies that regional climate dynamics is not deterministic with a (multi-)fractal phase space involving several spatio-temporal scales, where the interplay of long-term global phenomena with short-term local processes explains the great intra-regional variability. On practical matters, the q-index provides a unique physically based identifier of statistical complexity.

Tsallis' distributions provide valuable clues about dynamical affinity and the q-index can be used as an useful tool to compare model output (or any other dataset) with observations and define a criteria of goodness climate representation which encompasses several range of interactions and processes.

This statistical approach could be a useful forecast tool risk management in a climate change context since the differences of q-index for temperature and precipitation in the same location evidence intrinsic properties of how the extreme dynamics is expressed in each variable. The bounded/unbounded character of Tsallis' q-exponential distribution shape the nature of extreme behavior, in particular, information of return periods, range and probability for extreme events of interest can be easily obtained for estimated parameters.

Author Contributions: Conceptualization, Isabel Hoyos and Boris A. Rodríguez; Formal analysis, Isabel Hoyos; Funding acquisition, Boris A. Rodríguez; Methodology, Boris A. Rodríguez; Software, Isabel Hoyos; Visualization, Isabel Hoyos; Writing - review \& editing, Isabel Hoyos and Boris A. Rodríguez.

Conflicts of Interest: "The authors declare no conflict of interest."

1. McPhillips, L.E.; Chang, H.; Chester, M.V.; Depietri, Y.; Friedman, E.; Grimm, N.B.; Kominoski, J.S.; McPhearson, T.; Méndez-Lázaro, P.; Rosi, E.J.; Shiva, J.S. Defining Extreme Events: A Cross-Disciplinary Review. Earth's Future 2018, 6, 441-455. doi:10.1002/2017ef000686.

2. Balasis, G.; Donner, R.; Potirakis, S.; Runge, J.; Papadimitriou, C.; Daglis, I.; Eftaxias, K.; Kurths, J. Statistical Mechanics and Information-Theoretic Perspectives on Complexity in the Earth System. Entropy 2013, 15, 4844-4888. doi:10.3390/e15114844.

3. Sura, P. A general perspective of extreme events in weather and climate. Atmospheric Research 2011, 101,1-21. doi:10.1016/j.atmosres.2011.01.012. 
4. Donner, R.; Barbosa, S.; Kurths, J.; Marwan, N. Understanding the Earth as a Complex System - recent advances in data analysis and modelling in Earth sciences. The European Physical Journal Special Topics 2009, 174, 1-9. doi:10.1140/epjst/e2009-01086-6.

5. Kastens, K.A.; Manduca, C.A.; Cervato, C.; Frodeman, R.; Goodwin, C.; Liben, L.S.; Mogk, D.W.; Spangler, T.C.; Stillings, N.A.; Titus, S. How geoscientists think and learn. Eos Trans. AGU. 2009, 90, 265 - 266.

6. Turcotte, D.L. Modeling geocomplexity: "A new kind of science". In Special Paper 413: Earth and Mind: How Geologists Think and Learn about the Earth; Geological Society of America, 2006; pp. 39-50. doi:10.1130/2006.2413(04).

7. Franzke, C.L.E. Extremes in dynamic-stochastic systems. Chaos: An Interdisciplinary Journal of Nonlinear Science 2017, 27, 012101. doi:10.1063/1.4973541.

8. Sura, P. Maximum Entropy Production and Non-Gaussian Climate Variability. ArXiv e-prints 2016, [arXiv:physics.ao-ph/1603.05260].

9. Perron, M.; Sura, P. Climatology of Non-Gaussian Atmospheric Statistics. Journal of Climate 2013, 26, 1063-1083. doi:10.1175/jcli-d-11-00504.1.

10. Tsonis, A.A., Ed. Advances in Nonlinear Geosciences; Springer, 2018.

11. Pavlos, G.P.; Xenakis, M.N.; Karakatsanis, L.; Iliopoulos, A.C.; Pavlos, A.; Sarafopoulos, D. Universality of Tsallis non-extensive statistics and fractal dynamics for complex systems. ArXiv e-prints 2012, p. arXiv:1203.5556, [1203.5556].

12. Hanel, R.; Thurner, S. A comprehensive classification of complex statistical systems and an axiomatic derivation of their entropy and distribution functions. Europhysics Letters 2011, 93, 20006. doi:10.1209/0295-5075/93/20006.

13. Hanel, R.; Thurner, S. A comprehensive classification of complex statistical systems and an ab-initio derivation of their entropy and distribution functions. ArXiv e-prints 2010, [arXiv:physics.class-ph/1005.0138].

14. Tsallis, C. Introduction to Nonextensive Statistical Mechanics: Approaching a Complex World; Springer, 2009.

15. Gell-Mann, M.; Tsallis, C., Eds. Nonextensive Entropy: Interdisciplinary Applications; Oxford University Press, 2004.

16. Abe, S.; Okamoto, Y., Eds. Nonextensive Statistical Mechanics and Its Applications (Lecture Notes in Physics); Springer, 2001.

17. Beck, C. Dynamical Foundations of Nonextensive Statistical Mechanics. Physical Review Letters 2001, 87. doi:10.1103/physrevlett.87.180601.

18. Wilk, G.; Włodarczyk, Z. Interpretation of the Nonextensivity Parameterqin Some Applications of Tsallis Statistics and Lévy Distributions. Physical Review Letters 2000, 84, 2770-2773. doi:10.1103/physrevlett.84.2770.

19. Arimitsu, T.; Arimitsu, N. Analysis of turbulence by statistics based on generalized entropies. Physica A: Statistical Mechanics and its Applications 2001, 295, 177-194. doi:10.1016/s0378-4371(01)00072-3.

20. Bechle, A.J.; Wu, C.H. An entropy-based surface velocity method for estuarine discharge measurement. Water Resources Research 2014, 50, 6106-6128. doi:10.1002/2014wr015353.

21. Ferri, G.; Savio, M.R.; Plastino, A. Tsallis' -triplet and the ozone layer. Physica A: Statistical Mechanics and its Applications 2010, 389, 1829-1833. doi:10.1016/j.physa.2009.12.020.

22. Darooneh, A.H.; Dadashinia, C. Analysis of the spatial and temporal distributions between successive earthquakes: Nonextensive statistical mechanics viewpoint. Physica A: Statistical Mechanics and its Applications 2008, 387, 3647-3654. doi:10.1016/j.physa.2008.02.050.

23. Karakatsanis, L.; Iliopoulos, A.; Pavlos, E.; Pavlos, G. Statistical analysis of Geopotential Height (GH) timeseries based on Tsallis non-extensive statistical mechanics. Physica A: Statistical Mechanics and its Applications 2018, 492, 715-723. doi:10.1016/j.physa.2017.10.051.

24. Gonzalez, J.; de Faria, E.; Albuquerque, M.P.; Albuquerque, M.P. Nonadditive Tsallis entropy applied to the Earth's climate. Physica A: Statistical Mechanics and its Applications 2011, 390, 587-594. doi:10.1016/j.physa.2010.10.045.

25. Ausloos, M.; Petroni, F. Tsallis non-extensive statistical mechanics of El Niño southern oscillation index. Physica A: Statistical Mechanics and its Applications 2007, 373, 721-736. doi:10.1016/j.physa.2006.05.044. 
26. Petroni, F.; Ausloos, M. High frequency (daily) data analysis of the Southern Oscillation Index. Tsallis nonextensive statistical mechanics approach. The European Physical Journal Special Topics 2007, 143, 201-208. doi:10.1140/epjst/e2007-00088-8.

27. Yalcin, G.C.; Rabassa, P.; Beck, C. Extreme event statistics of daily rainfall: dynamical systems approach. Journal of Physics A: Mathematical and Theoretical 2016, 49, 154001. doi:10.1088/1751-8113/49/15/154001.

28. Keylock, C. Describing the recurrence interval of extreme floods using nonextensive thermodynamics and Tsallis statistics. Advances in Water Resources 2005, 28, 773-778. doi:10.1016/j.advwatres.2005.02.011.

29. Salas, H.; Poveda, G.; Mesa, O. Testing the Beta-Lognormal Model in Amazonian Rainfall Fields Using the Generalized Space q-Entropy. Entropy 2017, 19, 685. doi:10.3390/e19120685.

30. Poveda, G.; Salas, H.D. Statistical scaling, Shannon entropy, and Generalized space-time q-entropy of rainfall fields in tropical South America. Chaos: An Interdisciplinary Journal of Nonlinear Science 2015, 25, 075409. doi:10.1063/1.4922595.

31. Poveda, G. Mixed memory, (non) Hurst effect, and maximum entropy of rainfall in the tropical Andes. Advances in Water Resources 2011, 34, 243-256. doi:10.1016/j.advwatres.2010.11.007.

32. Hoyos, I.; Cañón-Barriga, J.; Arenas-Suárez, T.; Dominguez, F.; Rodríguez, B.A. Variability of regional atmospheric moisture over Northern South America: patterns and underlying phenomena. Climate Dynamics 2018. doi:10.1007/s00382-018-4172-9.

33. Hoyos, I.; Dominguez, F.; Cañón-Barriga, J.; Martínez, J.A.; Nieto, R.; Gimeno, L.; Dirmeyer, P.A. Moisture origin and transport processes in Colombia, northern South America. Climate Dynamics 2017. doi:10.1007/s00382-017-3653-6.

34. Arias, P.A.; Martínez, J.A.; Vieira, S.C. Moisture sources to the 2010-2012 anomalous wet season in northern South America. Clim Dyn 2015. doi:10.1007/s00382-015-2511-7.

35. Sakamoto, M.S.; Ambrizzi, T.; Poveda, G. Moisture sources and life cycle of convective systems over Western Colombia. Advances in Meteorology 2012, 2011, 1-11. doi:10.1155/2011/890759.

36. Poveda, G.; Jaramillo, L.; Vallejo, L.F. Seasonal precipitation patterns along pathways of South American low-level jets and aerial rivers. Water Resources Research 2014, 50, 98-118.

37. Insel, N.; Poulsen, C.J.; Ehlers, T.A. Influence of the Andes Mountains on South American moisture transport, convection, and precipitation. Clim Dyn 2009. doi:10.1007/s00382-009-0637-1.

38. Durán-Quesada, A.; Reboita, M.; Gimeno, L. Precipitation in tropical America and the associated sources of moisture: a short review. Hydrological Sciences Journal 2012, 57, 612-624.

39. Córdoba-Machado, S.; Palomino-Lemus, R.; Gámiz-Fortis, S.R.; Castro-Díez, Y.; Esteban-Parra, M.J. Assessing the impact of El Niño Modoki on seasonal precipitation in Colombia. Global and Planetary Change 2015, 124, 41-61. doi:10.1016/j.gloplacha.2014.11.003.

40. Córdoba-Machado, S.; Palomino-Lemus, R.; Gámiz-Fortis, S.R.; Castro-Díez, Y.; Esteban-Parra, M.J. Influence of tropical Pacific SST on seasonal precipitation in Colombia: prediction using El Niño and El Niño Modoki. Clim Dyn 2014, 44, 1293-1310. doi:10.1007/s00382-014-2232-3.

41. Hoyos, I.; Baquero-Bernal, A.; Jacob, D.; Rodríguez, B.A. Variability of extreme events in the Colombian Pacific and Caribbean catchment basins. Climate dynamics 2013, 40, 1985-2003.

42. Pabón, J. El Cambio Climático global y su manifestación en Colombia. Cuadernos Geografía 2003, 12, 111-119. 43. Waylen, P.R.; Poveda, G. El Niño-Southern Oscillation and aspects of western South America hydro-climatology. Hydrol Process 2002, 16, 1247-1260. doi:10.1002/hyp.1060.

44. Poveda, G.; Jaramillo, A.; Gil, M.M.; Quiceno, N.; Mantilla, R.I. Seasonality in ENSO-related precipitation, river discharges, soil moisture, and vegetation index in Colombia. Water Resour Res 2001, 37, 2169 - 2178.

45. Restrepo, J.D.; Kjerfve, B. Magdalena river: interannual variability (1975-1995) and revised water discharge and sediment load estimates. Journal of Hydrology 2000, 235, 137 - 149.

46. Carvajal, Y.E.; Jiménez, H.E.; Materón, H.M. Incidencia del fenómeno del Niño en la hidroclimatología del valle del río Cauca-Colombia. B Inst Fr Étud Andines 1998, 27, 743-751.

47. Ropelewski, C.F.; Halpert, M.S. Global and Regional Scale Precipitation Patterns Associated with the El Niño/Southern Oscillation. Monthly Weather Review 1987, 115, 1606-1626. doi:10.1175/1520-0493(1987)115<1606:garspp>2.0.co;2.

48. Hoyos, I.; Baquero-Bernal, A.; Hagemann, S. How accurately are climatological characteristics and surface water and energy balances represented for the Colombian Caribbean Catchment Basin? Climate Dynamics 2013, 41, 1269-1290. 
49. IDEAM. Atlas climatológico de Colombia; IDEAM, 2005.

50. Mesa, O.; Poveda, G.; Carvajal, L. Introducción al clima de Colombia; Universidad Nacional, 1997.

51. Snow, J.W. The climate of northern South America. In Climates of Central and South America; Schwerdtfeger, W., Ed.; Elsevier Scientific Publishing Co: Amsterdam, 1976; Vol. 12, World Survey of Climatology, pp. 295-403.

52. Sierra, J.P.; Arias, P.A.; Vieira, S.C. Precipitation over Northern South America and Its Seasonal Variability as Simulated by the CMIP5 Models. Advances in Meteorology 2015, 2015, 1-22. doi:10.1155/2015/634720.

53. Buytaert, W.; Biévre, B.D. Water for cities: The impact of climate change and demographic growth in the tropical Andes. Water Resources Research 2012, 48.

54. Hastings, D.A.; Dunbar, P.K. Development and assessment of the Global Land One-km Base Elevation Digital Elevation Model (GLOBE). The International Archives of the Photogrammetry, Remote Sensing and Spatial Information Sciences 1998, 32, 218-221.

55. Tsallis, C. Possible generalization of Boltzmann-Gibbs statistics. J Stat Phys 1988, 52, 479-487.

56. Tsallis, C.; Mendes, R.S.; Plastino, A.R. The role of constraints within generalized nonextensive statistics. Physica A 1998, 261, 534-554.

57. Bercher, J.F.; Vignat, C. A new look at q-exponential distributions via excess statistics. Physica A 2008, 387, 5422-5432.

58. Pickands, J. Statistical inference using extreme order statistics. Ann Stat 1975, 3, 119-131.

59. Poveda, G.; Álvarez, D.M.; Rueda, Ó.A. Hydro-climatic variability over the Andes of Colombia associated with ENSO: a review of climatic processes and their impact on one of the Earth's most important biodiversity hotspots. Climate Dynamics 2011, 36, 2233-2249. 